\title{
BRUMME, JENNY, Y HILDEGARD RESINGER (EDS.); ZABALLA, AMAIA (COLAB. EN ED.) (2008): LA ORALIDAD FINGIDA: DESCRIPCIÓN Y TRADUCCIÓN. MADRID/FRANKFURT AM MAIN: IBEROAMERICANA/VERVUERT, [175] PÁGS.
}

\author{
DANIEl M. SÁEZ Rivera \\ Universidad Complutense de Madrid \\ dansaez@filol.ucm.es
}

Continuación de La oralidad fingida: descripción y traducción. Teatro, cómic y medios audiovisuales (cf. Sáez Rivera, 2010), se presenta este volumen con una similar estructura e idéntica intención: analizar la presencia de rasgos orales en un medio a primera vista impropio para la inmediatez comunicativa, aunque esta vez en el ámbito más conocido de la novela (seis estudios), pero también el género menos estudiado de la sátira política (un estudio).

El volumen se abre también con un «Índice» de contenido (pág. [5]) y una sucinta «Introducción» (págs. [7]-8), en la que se presentan como únicas referencias el libro de Koch/Oesterriecher (2007 [1990]) y el volumen gemelo a este que nos ocupa, así como se recuerda el mismo método de conjugar una perspectiva intralingüística dentro de la cual se desgranan los recursos de una lengua concreta con la comparación interlingüística de diversas traducciones. A continuación, nuevamente se estampa una explicación de las «Abreviaturas» (págs. [9]), el conjunto de «Resúmenes en inglés / Abstracts» (págs. [11]-14), a lo que sigue el cuerpo del texto (siete contribuciones ordenadas alfabéticamente por el apellido de los autores) en las págs. [15] a 168, unos «Apuntes biográficos» (págs. [169]-173) igualmente por orden alfabético de apellido, y una breve tabla con el contenido del otro volumen de La oralidad fingida (pág. [175]). La factura editorial es igual de buena que en el otro caso, con sólo pocas erratas y algún error ortográfico o lingüístico ${ }^{1}$.

1 No obstante, la única errata detectada es bastante «visible», pues afecta al título consignado en la portadilla de la primera página, donde se consigna «La oralida fingida» en 
El primer artículo, de Victòria Alsina, versa sobre «El tratamiento del discurso indirecto libre en las traducciones españolas y catalana de Mansfield Park de Jane Austen» (págs. [15]-32). Aquí se compara el clásico de Jane Austen, de 1814, con la única traducción catalana existente (por M. Dolors Ventós, 1987) y dos traducciones al castellano (por Miguel Martín, Madrid, 1995; y por Francisco Torres, Barcelona, 1995), con la conclusión de que en este caso se aprecia una tendencia clara en todos los traductores a convertir el discurso indirecto libre (DIL) en otros tipos de discurso (directo, indirecto, narrativo), los rasgos de oralidad disminuyen de manera significativa en todas las traducciones y el punto de vista pasa del personaje a la narradora, con lo que se pierde gran parte de la polifonía textual originaria. Como única crítica podemos señalar que la autora no haya manejado ninguno de los trabajos de José Luis Girón sobre el discurso referido, que hubieran enriquecido su análisis: así, en el fragmento 1 nos encontramos más ante un discurso mixto (DM) de discurso directo e indirecto que ante DIL, y en el segundo párrafo las oraciones (7) y (8) son instancias del discurso narrado (DN) (cf. Girón Alconchel 1985).

El siguiente trabajo es un magnífico análisis de «La representación de la oralidad bilingüe en la literatura: Caramelo» (págs. [33]-58), por Yvette Bürki, donde se compara la novela Caramelo or puro cuento (2002) de la autora chicana Sandra Cisneros con su traducción al español como Caramelo o puro cuento (2003) por Liliana Valenzuela, con objeto de mostrar cómo se representa la oralidad de las variedades del inglés en contacto con el español y llamar la atención sobre los interrogantes que se plantean en su traducción al español. Tal traducción, según Bürki, ha sido bastante afortunada, al conseguir plasmar la oralidad concepcional del original inglés y su bilingüismo mediante diferentes recursos de compensación, en lugar de optar por una traducción homogeneizadora a la variedad americana del mexicano exclusivamente.

En cambio sí se neutraliza la oralidad fingida en la traducción al español de la sátira política de Michael Moore, según el estudio de Anna Espunya sobre «El reflejo del acento enfático en las traducciones española y catalana de Stupid White Men» (págs. [59]-77). Así, según la muestra analizada, tienden a suprimirse los rasgos orales como el acento enfático (marcado en el original con cursiva) sin ser compensados por medios sintácticos, con lo que se pierde parte

lugar de «La oralidad fingida». Vemos también que los correctores del texto, quizá de la editorial, siguen teniendo problemas con la correcta grafía de aparte: lo correcto es aparte de en «(a parte [sic] de su contribución a la marcha de la historia narrada)» (pág. 22). En el artículo de Gerda Haßler debe sustituirse en la pág. 132 «la anuncia» y «esta anuncia» por «el anuncio» y «este anuncio», además de que en el mismo capítulo sería recomendable sustituir «letra itálica» por «letra cursiva», denominación más frecuente en castellano para la también denominada «letra bastardilla». 
de la vivacidad y el tono provocador del original, mientras que en la versión catalana sólo en la mitad de casos se rebaja la oralidad vitriólica de Michael Moore. En todo caso, sería conveniente que se ampliara la muestra y el número de ejemplos analizados, así como realizar un estudio exhaustivo y cuantitativo para que estas conclusiones fueran más contundentes.

Quizá de menor interés, según mi opinión, es el siguiente trabajo, el cuarto del volumen, sobre «Los diálogos fragmentarios en el contexto de la novela Malina de Ingeborg Bachmann y su traducción» (págs. [79]-99), por Pilar Estelrich: sin una referencia a los estudios de oralidad u oralidad fingida, el artículo es casi un mero comentario de las traducciones de la novela Malina (1971) al castellano por Juan José Soler (1986) y al catalán por la propia Pilar Estelrich (2002), que sin embargo aporta su valiosa experiencia personal en el proceso y resultado de la traducción, además de que realiza una acertada contextualización de la obra y la figura de la autora del texto original.

En contraposición, el debido apoyo teórico se despliega en «El habla coloquial y vulgar en La sombra del viento: análisis ejemplar de su traducción al alemán, al inglés y al francés» (págs. [101]-119), por Francesc Fernández, que utiliza como referencias para el estudio del español coloquial trabajos de clásicos como Beinhauer, pero también de investigadores más recientes como Briz y Cortés, aparte de que para el análisis de traducción sigue el conocido modelo funcional de Nord. Al comparar las traducciones al alemán, al inglés y al francés del best-seller español, Fernández llega a la conclusión de que según «los veintiún ejemplos que integran el breve corpus» (pág. 117), es la versión francesa "posiblemente en razón de su mayor afinidad lingüística y cultural con el original, la más adecuada funcionalmente por lo que se refiere al conjunto de acciones comunicativas realizadas, seguida por las versiones alemana e inglés a un mismo nivel» (pág. 117). Sólo quizá podríamos reprochar el hecho de que, al igual que en el artículo sobre Stupid White Men, el análisis no sea exhaustivo, de modo que se hayan pasado por alto jugosos pasajes de la novela como en el que los protagonistas interaccionan comunicativamente con un camarero de acento andaluz y vulgarizante pero, curiosamente, nacido en Santa Coloma de Gramanet (Ruiz Zafón 2004[2001]: 212-213), un ejemplo magnífico de la interacción de variedades diasistemáticas en la cadena variacional que proponen Koch/Oesterreicher (2007[1990]), modelo que tampoco es manejado en esta contribución del segundo volumen de La oralidad fingida.

El penúltimo estudio del compendio también analiza las traducciones de un best-seller, pues en «Temas, remas, focos y tópicos en la oralidad fingida y en su traducción» (págs. [121]-143) Gerda Haßler emplea como corpus las traducciones castellana, portuguesa, italiana, francesa y alemana de la novela 
The Da Vinci Code de Dan Brown. Las conclusiones son similares o confluyentes con respecto a la de otros trabajos del mismo volumen: la falta de traducción de algunos recursos de oralidad fingida (como la letra cursiva -mejor que «itálica»-para indicar el foco, apenas empleada en las lenguas románicas con tal función; o el estilo de narración en tema continuo), que se hace con mayor o menor calado según la capacidad del traductor y los recursos o la retórica de cada lengua (así escaso en la traducción francesa).

Por último, Maria Wirf estudia «La ilusión de proximidad. Jurek Becker en alemán y en español» (págs. [145]-168). En concreto, la investigadora analiza la primera novela del autor, con el título de Jakob der Lügner (1969), y su traducción al castellano como Jakob el mentiroso (2000), por Manuel Olasagasti. Los elementos lingüísticos rastreados que revelan la oralidad de la novela son la disposición gráfica del texto (uso excesivo de la coma); los elementos deícticos; la elipsis y la repetición; el uso de los tiempos verbales y del discurso indirecto; un estilo escasamente nominal; y el recurso a tópicos, fraseología y partículas modales. Según Wirf, la traducción, globalmente buena, no siempre adopta o adapta los recursos oralizantes del original y tiende a una forma más canónica de lengua, aunque «consigue mantener la impresión global de fluctuación, típica del discurso oral menos proyectado y revisado, más abierto a digresiones y aportaciones espontáneas» (pág. 167).

En fin, como conclusión general de este volumen y del anterior, la tendencia general en las traducciones es a rebajar la oralidad fingida del original (en el peor de los casos) o en menos casos a compensarla (en las mejores traducciones).

\section{Referencias bibliográficas}

Girón Alconchel, José Luis (1985): «La "escritura del habla" y el discurso indirecto libre en español», Archivo de Filología Aragonesa, XXXVI-XXXVII, págs. 173-204

Koch, Peter, y Wulf Oesterreicher (2007[1990]): Lengua hablada en la Romania: español, francés, italiano (versión de Araceli López Serena). Madrid, Gredos [Trad. de: Gesprochene Sprache in der Romania: Französich, Italienisch, Spanisch. Tübingen, Max Niemeyer, 1990].

Ruiz Zafón, Carlos (2004[2001]): La sombra del viento. Barcelona, Planeta.

Sáez Rivera, Daniel M. (2010): «[Reseña:] Brumme, Jenny (ed.); Resinger, Hildegard, y Amaia Zaballa (colab. en ed.) (2008): La oralidad fingida: descripción y traducción. Teatro, cómic y medios audiovisuales. Madrid/Frankfurt am Main: Iberoamericana/Vervuert, [181] págs.», Revista de Filología Románica, 27, págs. 454-458. 